ORIGINAL ARTICLE

\title{
Expression of KRAS in tissue samples of colorectal carcinoma and its correlation with various histo-pathological parameters.
}

\author{
Hina Wasti ${ }^{1}$, Beenish Hussain Nomani ${ }^{2}$, Sehrish Shafique ${ }^{3}$, Yumna Shahid $^{4}$, Hira Faisal ${ }^{5}$
}

Article Citation: Wasti H, Nomani BH, Shafique S, Shahid Y, Faisal H. Expression of KRAS in Tissue Samples of Colorectal Carcinoma and Its Correlation with Various Histo-pathological Parameters. Professional Med J 2022; 29(1):94-100.

https://doi.org/10.29309/TPMJ/2022.29.01.6424

\begin{abstract}
Objective: To assess the expression of KRAS in tissue samples of colorectal carcinoma and to correlate it with histopathological parameters. Study Design: Cross Sectional study. Setting: Department of Pathology, PNS Shifa Hospital Karachi. Period: March 2016 to February 2019. Material \& Methods: A total of 51 cases of CRC were analyzed for immunohistochemical staining using KRAS antibody on representative tissue blocks. Clinical and pathological records were retrieved for collection of data. The results of immunohistochemical analysis were correlated with the recorded clinicopathological parameters. Results: In this study 51 cases of CRC were analyzed for immunoexpression of KRAS. The age of the patients ranged from 14 to 85 years with the mean age of 60.96 years. Among the 51 cases, $37(72.5 \%)$ cases were males and $14(27.4 \%)$ were females. $37(72.5 \%)$ were localized to left side colon and $14(27.4 \%)$ were found in the right colon. For KRAS immunostaining, 41(80.3\%) out of 51 cases showed overexpression. Significant association was seen between KRAS overexpression and histological variants i.e. glandular carcinomas. Conclusion: In the present study over expression of KRAS was observed in advanced tumors. Majority of these cases were adenocarcinomas with few showed mucinous histology. The present study signifies that established KRAS expression is usually seen in rapidly dividing cells with association of advanced tumors.
\end{abstract}

Key words: $\quad$ Colorectal Cancer, Clinicopathological Features, Immunohistochemistry, KRAS.

\section{INTRODUCTION}

Colorectal cancer represents almost $10 \%$ of all registered malignant diseases. Being the third leading cause of death word over, it is also the third most prevalent cancer in both male and female genders. ${ }^{1,2}$ The estimated 5-year prevalence rate is about 3.2 million. ${ }^{3,4}$ CRC incidence rises with age, up to $10 \%$ of CRC patients are younger than 50 years, the median age being $42-44$ years. About one million cases of colorectal cancer are diagnosed annually in the world. ${ }^{5}$

In Pakistan CRC accounts for $52 \%$ of all gastrointestinal tumors. ${ }^{6,7}$ Both environmental and genetic factors as well as various molecular pathways like chromosomal instability (CIN), microsatellite instability (MSI), and the CpG island methylation phenotype (CIMP) are responsible for the pathogenesis of colorectal cancer. These pathways are mediated by some important tumor suppressor genes and proto-oncogene.8,9 Among them KRAS proto-oncogene being the prime oncogenic factor for colorectal cancer plays a significant role in its pathogenesis. ${ }^{10}$

The RAS family is known as the most commonly mutated proto-oncogene which presents in all human malignancies including colorectal cancer. ${ }^{11}$ The most frequently occurring gene of RAS family is KRAS which mainly accounts for colorectal carcinogenesis. It possesses an important guanosine triphosphate/ guanosine diphosphate (GTP/GDP) binding properties which activates KRAS and leads to stimulation of MAPK and PI3K/ AKT signaling pathway, thereby causing rapid cell growth. The detection of KRAS expression
1. MBBS, M.Phil, Assistant Professor Pathology, Bahria University Medical \& Dental College, Karachi.

2. MBBS, M.Phil, Assistant Professor Histopathology, Bahria University Medical \& Dental College, Karachi.

3. MBBS, FCPS , Assistant Professor Medicine, Bahria University Medical \& Dental College, Karachi.

4. MBBS, Senior Lecturer Pathology, Bahria University Medical \& Dental College, Karachi.

5. MBBS, Senior Lecturer Pathology, Bahria University Medical \& Dental College, Karachi.

\author{
Correspondence Address: \\ Dr. Hina Wasti \\ Bahria University Medical \& \\ Dental College, Karachi. \\ drhinafaisal@gmail.com
}

Article received on:

Accepted for publication:
$12 / 02 / 2021$

$28 / 05 / 2021$ 
can be done by routine immunohistochemistry in histopathological laboratories. ${ }^{12}$ This study hence aims at evaluating expression of this marker in our population and to correlate it with various clinicopathological features in order to aid selection of effective treatment options.

\section{MATERIAL \& METHODS}

This cross sectional study was based on the analysis of colonic biopsies received in the Department of Pathology, PNS Shifa Hospital Karachi. After attaining Ethical approval (FRC/ BUMDC/Path/003) samples were collected including both biopsies and colectomy specimens. Sample size was calculated using software G- POWER (version 3.1.9.2), taking $95 \%$ confidence interval and $5 \%$ margin of error. The required sample size was found to be 51 . All colonic surgical specimens diagnosed as primary colorectal carcinoma obtained prior to therapy and patients who were willing to participate in the study were included, whereas poorly fixed tissue, inadequate material, metastatic tumors, post radiotherapy specimens as well as patients who refused to participate in the study were excluded from this research.

During the study period, from March 2016 to March 2019, 291 colorectal samples were received at our setup. Both biopsies $(n=29)$ and colectomy specimens $(n=22)$ were analyzed for histopathological diagnosis. Among them 240 cases were reported as benign lesions while 51 cases were diagnosed as colorectal cancer. Hematoxylin and eosin as well as anti-KRAS immunohistochemical staining was performed on the formalin-fixed paraffin-embedded tissues. The clinicopathological data including age, sex, location, microscopic types, and histological grade were collected for statistical analysis. For immunohistochemistry sections of 3 to $5 \mu \mathrm{m}$ thickness were taken from FFPE tumor blocks picked on poly-L-lysine coated slides. Antigen retrieval was done using retrieval solution $(\mathrm{pH}$ 6.0 citrate buffer $10 \mathrm{x}$ ) in water bath at 98-99 ㅇ $\mathrm{C}$ for 40 minutes. Endogenous peroxidase was blocked using hydrogen peroxide blocking solution. Primary antibodies were applied to cover the section. Sections were incubated for
30 min with labeled secondary antibody. DAB substrate chromogen solution $(1 \mathrm{ml}$ substrate buffer +1 drop DAB chromogen) was applied to cover section, incubated for 2 minutes, washed and counterstained with hematoxylin, dehydrated with ethanol, cleared in xylene and mounted. The slides were then visualized under a light microscope. Tissue samples to which no primary antibody had been added were used as negative controls.

Immunoreactivity was scored taking into account the percentage of stained tumor cells (Yellow brown color) and intensity of staining. For KRAS membranous staining was scored as $3(+)$ when the majority of cells $(>75 \%)$ showed positive staining, 2(+) when $50-75 \%$ and $1(+)$ when $25-50 \%$ of cells were stained. The staining was taken as negative when $<25 \%$ cells revealed staining with KRAS protein. Scores $3(+), 2(+)$ and $1(+)$ were considered as expression of KRAS protein. The intensity of KRAS staining was graded as strong $(3+)$, moderate $(2+)$ weak $(1+)$ and no staining (0). Human Placental tissue was used as positive control. Statistical analysis was done using SPSS version 23.0 Continuous variables were presented as mean and standard deviation. Categorical variables were presented as frequency and percentage. $\mathrm{P} \leq 0.05$ was considered statistically significant.

\section{RESULTS}

Among 51 cases subjected to KRAS immunostaining, 41 cases showed overexpression of KRAS. The positivity was strong $(3+)$ in 23 cases, moderate $(2+)$ in 20 cases. The remaining 8 cases showed weak staining intensity $(1+)$ with KRAS protein on immunohistochemistry.

In this study 51 cases of colorectal carcinomas were included, among them 16 showed mucinous histology with signet ring cells, 1 showed cribriform pattern, 2 were poorly cohesive tumors, while the rest 32 were adenocarcinomas.

Table-I shows intensity and extent of immunoexpression of KRAS protein in diagnosed malignant cases of colorectal samples. Out of 51 cases of colorectal cancer 23 cases showed 
strong staining for KRAS protein with 18 cases showing strong reactivity in $>75 \%$ of tumor cells, 3 cases showed strong reaction in almost $60 \%$ of cells, 1 case had strong reactivity in $>50 \%$ of tumor cells and 1 case showed strong reactivity in $<25 \%$ of tumor cells.

Table-Il compares the extent and intensity of KRAS immunoreactivity according to degree of differentiation in colorectal cancers. From 32 well differentiated cases of adenocarcinomas 16(50) $\%$ of cases showed strong intensity for KRAS protein in $>75 \%$ of tumor cells. The remaining 16 cases showed weak to moderate staining in $60 \%$ of neoplastic cells.

Among 14 cases of moderately differentiated carcinoma only 1 case showed strong intensity in $>75 \%$ of tumor cells, the remaining 3 cases showed strong reaction in approximated $60 \%$ of tumor cells. 2 out of 5 cases of poorly differentiated carcinoma showed strong intensity in $>75 \%$ of tumor cells, while remaining 3 showed weak to moderate staining intensity in $60 \%$ of tumor cells.

Table-III correlates the expression of KRAS with different clinicopathological parameters. Total 51 cases of malignant colorectal cancer included in the present study, were evaluated by immunostaining of KRAS protein. The age of the patients ranged from 10-89 years with the highest occurrence found to be in 50-59 years age group.

Out of 37 male patients, 29 cases showed positive expression i.e, moderate $(2+)$ to strong $(3+)$ while remaining 8 cases were associated with either weak or no KRAS immunoexpression. In female gender total 14 cases were diagnosed as malignant colorectal cancer. Out of them 12 cases showed moderate to strong expression of
KRAS protein while 2 cases revealed weak/focal expression.

Thirty seven out of 51 cases of colorectal cancers were localized to the left side. Among them 30 cases showed strong to moderate immunoreactivity, whereas 7 cases showed weak or no expression of KRAS. 14 malignant cases were found to be involving the right colon, 11 out them showed moderate to strong expression while remaining 3 cases of right sided tumor revealed weak or negative immunoreactivity with KRAS protein.

Inthis studypositive KRASexpressionwas detected in 32 cases of glandular adenocarcinoma. 29 cases with glandular histology showed KRAS over expression. 3 cases of adenocarcinoma showed weak or negative KRAS protein expression.

12 out of 16 cases of mucinous and signet ring cancers revealed KRAS over expression, whereas 4 cases expressed weak or no immunoreactivity. Other histological variants observed in this study include 2 cases diagnosed as poorly cohesive tumors which showed no association with KRAS over expression. While one case showed cribriform pattern and showed with negative KRAS expression on immunohistochemistry.

Extent of reactivity: 0, <25\%; $1+, 25-50 \% ; 2+$, $50-75 \% ; 3+,>75 \%$ Intensity of reactivity: $0=$ no staining; $1+=$ weak staining; $2+=$ moderate staining, $3+=$ strong staining.

Extent of reactivity: $0,<25 \% ; 1+, 25-50 \% ; 2+$, $50-75 \%$; $3+,>75 \%$.

Intensity of reactivity: $0=$ no staining; $1+=$ weak staining; $2+=$ moderate staining, $3+=$ strong staining.

\begin{tabular}{|c|c|c|c|c|c|c|c|c|}
\hline \multicolumn{4}{|c|}{ Extent } & \multicolumn{4}{|c|}{ Intensity } & \multirow[t]{2}{*}{ Total } \\
\hline 0 & 1 & 2 & 3 & 0 & 1 & 2 & 3 & \\
\hline $2(25 \%)$ & $3(37.5 \%)$ & $1(12.5 \%)$ & $2(25 \%)$ & $0(0 \%)$ & $8(100 \%)$ & $0(0 \%)$ & $0(0 \%)$ & 8 \\
\hline $1(5 \%)$ & $5(25 \%)$ & 3 (15\%) & $11(55 \%)$ & $0(0 \%)$ & $0(0 \%)$ & 20 (100\%) & $0(0 \%)$ & 20 \\
\hline $1(4.3 \%)$ & $1(4.3 \%)$ & 3 (13.04\%) & $18(78.2 \%)$ & $0(0 \%)$ & $0(0 \%)$ & $0(0 \%)$ & 23 (100\%) & 23 \\
\hline
\end{tabular}




\begin{tabular}{|c|c|c|c|c|c|c|c|c|c|}
\hline \multirow{2}{*}{ Histological Grades } & \multirow{2}{*}{$\begin{array}{l}\text { Total no } \\
\text { of Cases }\end{array}$} & \multicolumn{4}{|c|}{ Extent } & \multicolumn{4}{|c|}{ Intensity } \\
\hline & & 0 & 1 & 2 & 3 & 0 & 1 & 2 & 3 \\
\hline Well differentiated carcinoma (G1) & $\begin{array}{c}32 \\
(62.7 \%)\end{array}$ & $\begin{array}{c}2 \\
(6.2 \%)\end{array}$ & $\begin{array}{c}5 \\
(15 \%)\end{array}$ & $\begin{array}{c}5 \\
(15 \%)\end{array}$ & $\begin{array}{c}20 \\
(62 \%)\end{array}$ & $\begin{array}{c}0 \\
(0 \%)\end{array}$ & $\begin{array}{c}5 \\
(15 \%)\end{array}$ & $\begin{array}{c}11 \\
(34 \%)\end{array}$ & $\begin{array}{c}16 \\
(50 \%)\end{array}$ \\
\hline $\begin{array}{l}\text { Moderately differentiated carcinoma } \\
\text { (G2) }\end{array}$ & $\begin{array}{c}14 \\
(27.4 \%)\end{array}$ & $\begin{array}{c}1 \\
(20 \%)\end{array}$ & $\begin{array}{c}3 \\
(21 \%)\end{array}$ & $\begin{array}{c}3 \\
(21 \%)\end{array}$ & $\begin{array}{c}7 \\
(50 \%)\end{array}$ & $\begin{array}{c}0 \\
(0 \%)\end{array}$ & $\begin{array}{c}2 \\
(14 \%)\end{array}$ & $\begin{array}{c}8 \\
(57 \%)\end{array}$ & $\begin{array}{c}4 \\
(28 \%)\end{array}$ \\
\hline
\end{tabular}

Table-II. Relationship between KRAS immunostaining and histological grades. $(n=51)$

\begin{tabular}{|c|c|c|c|c|}
\hline \multirow[t]{2}{*}{ Clinicopathogical Features } & \multirow[t]{2}{*}{ Total Numbers } & \multicolumn{2}{|c|}{ KRAS Over Expression } & \multirow[t]{2}{*}{ P-Value } \\
\hline & & Positive & Negative & \\
\hline \multirow{2}{*}{ Gender } & Male $=37$ & 29 & 8 & \multirow{2}{*}{0.707} \\
\hline & Female $=14$ & 12 & 2 & \\
\hline \multirow{2}{*}{ Tumor Location } & Right-sided $=14$ & 11 & 3 & \multirow{2}{*}{1.00} \\
\hline & Left-sided $=37$ & 30 & 7 & \\
\hline Glandular Adenocarcinoma & $32(62.7 \%)$ & 29 & 3 & \multirow{4}{*}{0.003} \\
\hline Mucinous Carcinoma/Signet ring & $16(31.4 \%)$ & 12 & 4 & \\
\hline Poorly cohesive & $2(3.9 \%)$ & 0 & 2 & \\
\hline Ciribriform pattern & $1(2.0 \%)$ & 0 & 1 & \\
\hline
\end{tabular}

Table-III. Association of clinicopathological features with KRAS overexpression. $(n=51)$

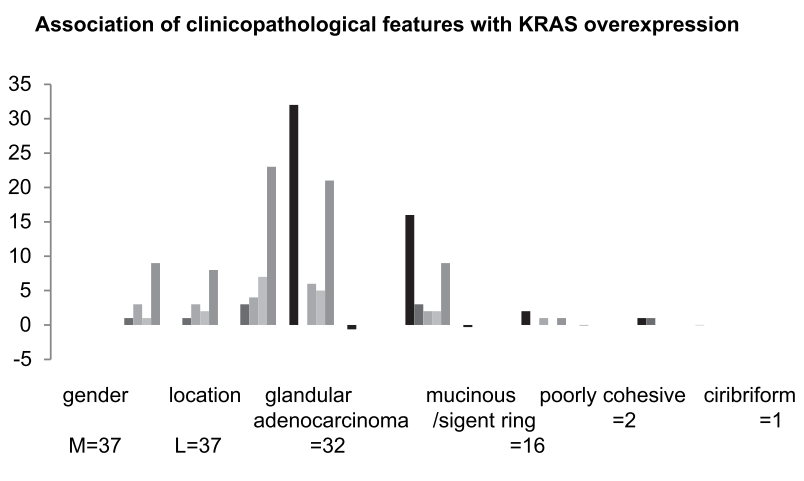

Figure-1

\section{DISCUSSION}

This study has been done with the aim to determine the frequency of colorectal cancers received at our setup and to evaluate the overexpression of KRAS proto oncogene as an established marker in advanced tumors.

In the present study the mean age for colorectal carcinoma was found to be 60.96 years. These findings are similar with the figures documented in Shaukat Khanum Memorial Cancer Hospital, Lahore, Pakistan. According to which the estimated mean age for males and females were reported as 53 years and 50 years respectively. ${ }^{13}$ Whereas a study which included 131 young patients, showed comparatively lower mean age which was documented as 33.3 years. This distinction may be attributed to the sample size variation. ${ }^{14}$

In the present study out of 51 cases of colorectal carcinomas, $37(72.5 \%)$ cases were present in males, while the remaining $14(27.4 \%)$ cases of colorectal cancer were seen in females. Similar results were reported in a study showing that colorectal cancer was diagnosed in $65.8 \%$ male and $34.2 \%$ of female patients. ${ }^{15}$

In the present study most commonly observed grade was well differentiated adenocarcinoma, whereas the common microscopic variants were reported as adenocarcinoma, and mucinoussignet ring type carcinoma. A study reported similar histological variants such as $22(84.6 \%)$ cases of adenocarcinoma, $2(7.7 \%)$ cases of mucinous carcinoma, and $2(7.7 \%)$ cases as signet ring cell carcinomas. ${ }^{12}$ There is an ambiguity in a study where most of the cases of 
colorectal cancer were identified as moderate to poorly differentiated tumors. ${ }^{16}$

In the present study on KRAS immunostaining, out of 51 cases, $41(80.39 \%)$ cases of colorectal cancer showed over expression for KRAS protein while remaining $10(19.60 \%)$ cases revealed no expression of KRAS on IHC. These results are in agreement with other studies which concluded positive expression for KRAS protein on IHC. 17,18,19 Various studies showed overexpression of KRAS, BRAF, MEK, and ERK both by IHC and $q$ PCR and suggested that $\mathrm{IHC}$ to be an equally effective diagnostic technique. ${ }^{20,21}$

In the current study we observed the association of KRAS over expression with different clinicopathological parameters including, age, gender, tumor localization, tumor grades and histological variants. Patient's age, gender and tumor location did not reveal any significant correlation with KRAS overexpression in colorectal cancer patient in our population. Our results are in agreement with some other studies which reported no significant relation between age, gender and tumor laterality with KRAS over expression in colorectal cancer patient. ${ }^{22,23}$ Histological variants however, revealed a significant correlation with KRAS over expression in the present study. Other studies have also shown significant association between KRAS expression and histological variants. ${ }^{13,24}$

As the present study has utilized immunohistochemistry to evaluate expression of KRAS protein in colorectal cancer, we can use our results as a foundation for further researches evaluation KRAS expression. Molecular analysis would be required to strength the results in future.

The limitations of the study included data from single tertiary represent the general population. Further large scale multicentric studies will be required to assess the burden of mutations in our population. Additional, relevant clinical data could not be ascertained because of inaccessibility to the record files.

\section{CONCLUSION}

In the present study over expression of KRAS was observed in advanced tumors. Majority of these cases were adenocarcinomas with few showed mucinous histology. The present study signifies that established KRAS expression is usually seen in rapidly dividing cells with association of advanced tumors.

Copyright(C) 28 May, 2021.

\section{REFERENCES}

1. Zdravkovic N, Pavlovic M, Radosavljevic G, Jovanovic I, Arsenijevic A, Zdravkovic N, Maric V, Loncarevic S, Srzentic Z, Jovanovic I. Serum levels of immunosuppressive cytokines and tumor markers in metastatic colorectal carcinoma. JBUON. 2017; 22(5):1-8.

2. Pollett A. Colorectal carcinoma. InAtlas of Intestinal Pathology 2019 (pp. 15-25). Springer, Cham.

3. Ferlay J, Soerjomataram I, Ervik M, Dikshit R, Eser S, Mathers C, Rebelo M, Parkin DM, Forman D, Bray F. GLOBOCAN 2012: Estimated Cancer Incidence, Mortality and Prevalence Worldwide in 2012 v1.0. IARC Cancer Base No. 11 [Online]. Lyon, France: International Agency for Research on Cancer.

4. Bray F, Ren JS, Masuyer E, Ferlay J. Global estimates of cancer prevalence for 27 sites in the adult population in 2008. International journal of cancer. 2018 Mar 1; 132(5):1133-45.

5. Liu SL, Cheung WY. Role of surveillance imaging and endoscopy in colorectal cancer follow-up: Quality over quantity. World journal of gastroenterology. 2019 Jan $7 ; 25(1): 59$.

6. Zhang S, Chen Y, Zhu Z, Ding Y, Ren S, Zuo Y. Differential expression of carbohydrate antigen 199 in human colorectal cancer: A comparison with colon and rectal cancers. Molecular and clinical oncology. 2013 Nov $1 ; 1(6): 1072-8$.

7. Hohenberger W. Colorectal cancer-heading to the future. Innovative surgical sciences. 2018 Mar 9; 3(1):12.

8. Mármol I, Sánchez-de-Diego C, Pradilla Dieste A, Cerrada E, Rodriguez Yoldi MJ. Colorectal carcinoma: A general overview and future perspectives in colorectal cancer. International journal of molecular sciences. 2017 Jan; 18(1):197. 
9. Nikolouzakis TK, Vassilopoulou L, Fragkiadaki P, Mariolis Sapsakos T, Papadakis GZ, Spandidos DA, Tsatsakis AM, Tsiaoussis J. Improving diagnosis, prognosis and prediction by using biomarkers in CRC patients. Oncology reports. 2018 Jun 1; 39(6):2455-72.

10. Roma C, Rachiglio AM, Pasquale R, Fenizia F, lannaccone A, Tatangelo F, Antinolfi G, Parrella P, Graziano P, Sabatino L, Colantuoni V. BRAF V600E mutation in metastatic colorectal cancer: Methods of detection and correlation with clinical and pathologic features. Cancer biology \& therapy. 2016 Aug 2; 17(8):840-8.

11. Saeed O, Lopez-Beltran A, Fisher KW, Scarpelli M, Montironi R, Cimadamore A, Massari F, Santoni M, Cheng L. RAS genes in colorectal carcinoma: pathogenesis, testing guidelines and treatment implications. Journal of clinical pathology. 2019 Feb 1; 72(2):135-9.

12. Elsabah MT, Adel I. Immunohistochemical assay for detection of K-ras protein expression in metastatic colorectal cancer. Journal of the Egyptian National Cancer Institute. 2013 Mar 1; 25(1):51-6.

13. Hussain $M$, Waqas $O$, Hassan $U$, Loya $A$, Akhtar $N$, Mushtaq S, Yusuf MA, Syed AA. Right-sided and left-sided colon cancers are two distinct disease entities: An analysis of $\mathbf{2 0 0}$ cases in Pakistan. Asian Pac J Cancer Prev. 2016 Jan 1; 17(5):2545-8.

14. Zahir MN, Azhar EM, Rafiq S, Ghias K, ShabbirMoosajee M. Clinical features and outcome of sporadic colorectal carcinoma in young patients: A cross-sectional analysis from a developing country. International Scholarly Research Notices. 2014; 2014.

15. Tsai $\mathrm{YJ}$, Huang SC, Lin HH, Lin CC, Lan YT, Wang HS, Yang SH, Jiang JK, Chen WS, Lin TC, Lin JK. Differences in gene mutations according to gender among patients with colorectal cancer. World journal of surgical oncology. $2018 \mathrm{Dec} ; 16(1): 1-5$.

16. Hashmi AA, Hashmi SK, Ali N, Thara K, Ali R, Edhi $M M$, Faridi N, Khan A. Clinicopathologic features of colorectal carcinoma: Features predicting higher T-stage and nodal metastasis. BMC research notes. 2018 Dec; 11(1):1-6.
17. Zlatian OM, Comănescu MV, Roşu AF, Roşu LU, Cruce M, Găman AE, Călina CD, Sfredel V. Histochemical and immunohistochemical evidence of tumor heterogeneity in colorectal cancer. Romanian journal of morphology and embryology $=$ Revue roumaine de morphologie et embryologie. 2015 Jan 1; 56(1):175-81.

18. Piton N, Borrini F, Bolognese A, Lamy A, Sabourin JC. KRAS and BRAF mutation detection: Is immunohistochemistry a possible alternative to molecular biology in colorectal cancer. Gastroenterology research and practice. 2015 Apr 23; 2015.

19. Yang Q, Huo S, Sui Y, Du Z, Zhao H, Liu Y, LiW, Wan X, Liu T, Zhang G. Mutation status and immunohistochemical correlation of KRAS, NRAS, and BRAF in 260 chinese colorectal and gastric cancers. Frontiers in oncology. 2018 Oct 26; 8:487.

20. Wan XB, Wang AQ, Cao J, Dong ZC, Li N, Yang S, Sun MM, Li Z, Luo SX. Relationships among KRAS mutation status, expression of RAS pathway signaling molecules, and clinicopathological features and prognosis of patients with colorectal cancer. World journal of gastroenterology. 2019 Feb 21; 25(7):808.

21. Kim JK, Seong CY, Bae IE, Yi JW, Yu HW, Kim SJ, Won JK, Chai YJ, Choi JY, Lee KE. Comparison of immunohistochemistry and direct sequencing methods for identification of the BRAF V600E mutation in papillary thyroid carcinoma. Annals of surgical oncology. 2018 Jun; 25(6):1775-81.

22. Al-Shamsi HO, Jones J, Fahmawi Y, Dahbour I, Tabash A, Abdel-Wahab R, Abousamra AO, Shaw KR, Xiao L, Hassan MM, Kipp BR. Molecular spectrum of KRAS, NRAS, BRAF, PIK3CA, TP53, and APC somatic gene mutations in Arab patients with colorectal cancer: Determination of frequency and distribution pattern. Journal of gastrointestinal oncology. 2016 Dec; 7(6):882.

23. Xie MZ, Li JL, Cai ZM, Li KZ, Hu BL. Impact of primary colorectal Cancer location on the KRAS status and its prognostic value. BMC gastroenterology. $2019 \mathrm{DeC}$; 19(1):1-9.

24. Bisht S, Ahmad F, Sawaimoon S, Bhatia S, Das BR. Molecular spectrum of KRAS, BRAF, and PIK3CA gene mutation: Determination of frequency, distribution pattern in Indian colorectal carcinoma. Medical oncology. 2014 Sep 1; 31(9):124. 


\section{AUTHORSHIP AND CONTRIBUTION DECLARATION}

\begin{tabular}{|c|l|l|l|}
\hline No. & \multicolumn{1}{|c|}{ Author(s) Full Name } & \multicolumn{1}{c|}{ Contribution to the paper } & Author(s) Signature \\
\hline 1 & Hina Wasti & $\begin{array}{l}\text { Conceived idea, Study designed, } \\
\text { Data collection, Results interpretation, } \\
\text { Manuscript writing. } \\
\text { Data collection, Immuno hinto-chemical } \\
\text { analysi. }\end{array}$ \\
3 & Sehrish Shafique & $\begin{array}{l}\text { Results interpretation, Proof reading \& } \\
\text { correction of manuscript. } \\
\text { Data collection, Helped to draft the } \\
\text { manuscript. } \\
4\end{array}$ & $\begin{array}{l}\text { Yumna Shahid } \\
\text { Proof reading, Helped to draft the } \\
\text { manuscript. }\end{array}$ \\
\hline 5 & Hira Faisal &
\end{tabular}

